\title{
Presence of a Congenitally Bicuspid Aortic Valve Among Patients Having Combined Mitral and Aortic Valve Replacement
}

\author{
William Clifford Roberts, MD ${ }^{\mathrm{a}, \mathrm{b}, \mathrm{d}, *}$, Kaitlin Georgeanne Janning ${ }^{\mathrm{d}, \mathrm{e}}$, \\ Travis James Vowels ${ }^{\text {d,f, Jong Mi Ko, BA }}{ }^{\mathrm{d}}$, Baron Lloyd Hamman, MD ${ }^{\mathrm{c}}$, and \\ Robert Frederick Hebeler, Jr., MD
}

\begin{abstract}
Although bicuspid aortic valve occurs in an estimated $1 \%$ of adults and mitral valve prolapse in an estimated 5\% of adults, occurrence of the 2 in the same patient is infrequent. During examination of operatively excised aortic and mitral valves because of dysfunction (stenosis and/or regurgitation), we encountered 16 patients who had congenitally bicuspid aortic valves associated with various types of dysfunctioning mitral valves. Eleven of the 16 patients had aortic stenosis (AS): 5 of them also had mitral stenosis, of rheumatic origin in 4 and secondary to mitral annular calcium in 1 ; the other 6 with aortic stenosis had pure mitral regurgitation (MR) secondary to mitral valve prolapse in 3 , to ischemia in 2 , and to unclear origin in 1 . Of the 5 patients with pure aortic regurgitation, each also had pure mitral regurgitation: in 1 secondary to mitral valve prolapse and in 4 secondary to infective endocarditis. In conclusion, various types of mitral dysfunction severe enough to warrant mitral valve replacement occur in patients with bicuspid aortic valves. A proper search for mitral valve dysfunction in patients with bicuspid aortic valves appears warranted. (c) 2012 Elsevier Inc. All rights reserved. (Am J Cardiol 2012;109:263-271)
\end{abstract}

In 1994 Fernicola and Roberts ${ }^{1}$ described morphologic features of operatively excised aortic and mitral valves in 12 patients who had undergone combined aortic and mitral valve replacement for dysfunctioning congenitally bicuspid aortic valves (aortic stenosis [AS] in 8 and pure aortic regurgitation [AR] in 4) and dysfunctioning mitral valves (mitral regurgitation [MR] in 11 and congenital mitral stenosis $[\mathrm{MS}]$ in 1$)$. The 12 patients (10\%) were from 115 having combined mitral and aortic valve replacement. The present report examines at another institution 16 patients who had undergone combined aortic and mitral valve replacement for dysfunctioning congenitally bicuspid aortic valves and dysfunctioning mitral valves to demonstrate again the relative frequency of structural mitral disease in patients with dysfunctioning congenitally bicuspid aortic valves.

\section{Methods}

At Baylor University Medical Center (BUMC) at Dallas from March 3, 1993 to July 8, 2011, 3,054 native valve replacement operations were performed (Figure 1). Of that number, 2866 (94\%) involved a single valve (aortic in 2,174, mitral in 677, and tricuspid in 15) and $169(6 \%)$ the replacement of $>1$ cardiac valve (mitral and aortic valves in

\footnotetext{
${ }^{a}$ Departments of Internal Medicine (Cardiology), ${ }^{b}$ Pathology, and ${ }^{\mathrm{c}}$ Cardiothoracic Surgery and ${ }^{\mathrm{d} B a y l o r}$ Heart and Vascular Institute, Baylor University Medical Center, Dallas, Texas; ${ }^{\mathrm{e}}$ Furman University, Greenville, South Carolina; ${ }^{\mathrm{f}}$ University of Texas at Austin, Austin, Texas. Manuscript received August 16, 2011; revised manuscript received and accepted September 2, 2011.

*Corresponding author: Tel: 214-820-7911; fax: 214-820-7533.

E-mail address: wc.roberts@baylorhealth.edu (W.C. Roberts).
}

180 and tricuspid plus $\geq 1$ other valve in 8 ). Of the 180 who had left-sided double valve replacements, $16(9 \%)$ were in patients having a stenotic or purely regurgitant congenitally bicuspid aortic valve and a stenotic or purely regurgitant mitral valve. These 16 patients are the subject of this report. All 32 valves from these 16 patients were examined in the cardiovascular pathology laboratory of BUMC at Dallas, a part of the surgical pathology department, by 1 of us (W.C.R.). Photographs of the operatively excised valves were taken by 1 of us (J.M.K.). Histologic sections after the gross photographs were prepared from the valves that were the sites of infective endocarditis and from the mitral valves considered on gross examination to be characteristic of mitral valve prolapse. Stenotic valves were not studied histologically.

Medical records and available echocardiographic, hemodynamic, and angiographic reports were acquired on all 16 patients. Records of death were obtained from the Social Security Death Index. Intervals from the time of combined mitral and aortic valve replacement to June 30, 2011, were calculated.

\section{Results}

Pertinent findings in the 16 patients are presented in Tables 1 and 2 and illustrated in 13 patients in Figures 2 through 14 . Of the 16 patients, 12 were men age 24 to 77 (mean 57) and 4 were women age 53 to 84 (mean 67). Fifteen were white (94\%) and 1 was Hispanic (6\%, case 2).

Patients were divided into 3 major groups: (1) those with combined AS (with or without AR) and MS (cases 1 to 5; Tables 1 and 2), (2) those with AS and pure MR (cases 6 to 11; Tables 1 and 2), and (3) those with combined pure AR 


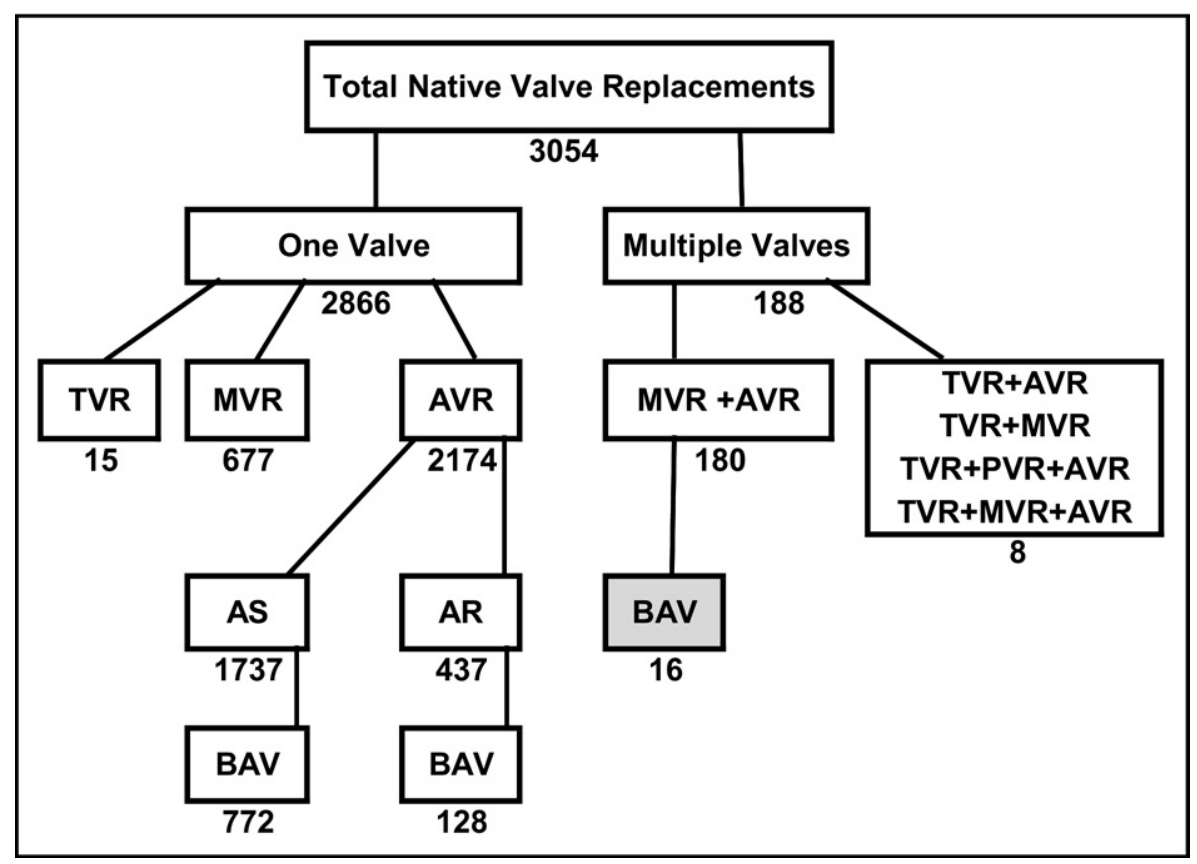

Figure 1. Flow chart of types of cardiac valve replacement operations at Baylor University Medical Center at Dallas from March 3, 1993 through July 8, 2011. $\mathrm{AR}=$ aortic regurgitation; $\mathrm{AS}=$ aortic stenosis; $\mathrm{AVR}=$ aortic valve replacement; $\mathrm{BAV}=$ bicuspid aortic valve; MVR = mitral valve replacement; $\mathrm{PVR}=$ pulmonary valve replacement; TVR $=$ tricuspid valve replacement.

Table 1

Pertinent clinical findings in patients with bicuspid aortic valves and dysfunctioning mitral valves with replacement of the two

\begin{tabular}{|c|c|c|c|c|c|c|c|c|c|c|c|c|c|c|c|}
\hline $\begin{array}{l}\text { Case Number } \\
\text { (figure number) }\end{array}$ & $\begin{array}{c}\text { Age } \\
\text { (years)/ } \\
\text { Sex }\end{array}$ & $\begin{array}{l}\text { AVR to } \\
\text { Discharge } \\
\text { (days) }\end{array}$ & $\begin{array}{c}\text { AVR to } \\
\text { Death (days) }\end{array}$ & CABG & AS & $\mathrm{AR}$ & MS & MR & IE & RHD & IMR & MVP & MAC & $\begin{array}{c}\text { Preoperative } \\
\text { AF }\end{array}$ & $\begin{array}{c}\text { BMI } \\
\left(\mathrm{kg} / \mathrm{m}^{2}\right)\end{array}$ \\
\hline 2 & $50 / \mathrm{M}$ & 9 & 3,704 & + & + & 0 & + & 0 & 0 & + & 0 & 0 & 0 & $0^{\dagger}$ & 27 \\
\hline $3(3)$ & $46 / \mathrm{M}$ & 4 & 2,534 & $0^{*}$ & + & 0 & + & 0 & 0 & + & 0 & 0 & 0 & + & 26 \\
\hline $4(4)$ & $74 / \mathrm{F}$ & 13 & 4,856 & 0 & + & 0 & + & 0 & 0 & + & 0 & 0 & 0 & + & 21 \\
\hline $5(5)$ & $71 / \mathrm{M}$ & 12 & alive $(1,162)$ & + & + & 0 & + & 0 & 0 & 0 & 0 & 0 & + & 0 & 35 \\
\hline 7 (7) & 77/M & 7 & 867 & + & + & 0 & 0 & + & 0 & 0 & + & 0 & 0 & $0^{\dagger}$ & 22 \\
\hline $8(8)$ & $58 / \mathrm{F}$ & 6 & alive $(1,301)$ & 0 & + & 0 & 0 & + & 0 & 0 & 0 & 0 & 0 & 0 & 42 \\
\hline $9(9)$ & $68 / \mathrm{M}$ & 6 & 1,540 & 0 & + & 0 & 0 & + & 0 & 0 & 0 & + & 0 & 0 & 23 \\
\hline $10(10)$ & $67 / \mathrm{M}$ & 6 & alive $(1,267)$ & 0 & + & 0 & 0 & + & 0 & 0 & 0 & + & 0 & $0^{\dagger}$ & 24 \\
\hline $11(11)$ & $66 / \mathrm{M}$ & 7 & 472 & 0 & + & 0 & 0 & + & 0 & 0 & 0 & + & 0 & 0 & 27 \\
\hline 12 & $48 / \mathrm{M}$ & 56 & alive $(6,096)$ & + & 0 & + & 0 & + & 0 & 0 & 0 & + & 0 & + & - \\
\hline
\end{tabular}

$\mathrm{AF}=$ atrial fibrillation; $\mathrm{AR}=$ aortic regurgitation; $\mathrm{AS}=$ aortic stenosis; $\mathrm{AVR}=$ aortic valve replacement $\mathrm{BMI}=$ body mass index; $\mathrm{CABG}=$ coronary artery bypass grafting; $\mathrm{F}=$ female; $\mathrm{IE}=$ infective endocarditis; IMR = ischemic mitral regurgitation; $\mathrm{M}=$ male; MAC = mitral annular calcium; $\mathrm{MR}=$ mitral regurgitation; $\mathrm{MS}=$ mitral stenosis; $\mathrm{MVP}=$ mitral valve prolapse; $\mathrm{RHD}=$ rheumatic heart disease.

* Previous resection of aortic isthmic coarctation.

${ }^{\dagger}$ Developed atrial fibrillation postoperatively after double-valve replacement. 
Table 2

Hemodynamic findings, valve weights, and substitute valves employed in 16 patients with bicuspid aortic valves, mitral dysfunction, and replacement of two left-sided valves

\begin{tabular}{|c|c|c|c|c|c|c|c|c|c|c|c|c|c|c|c|c|c|}
\hline \multirow[t]{2}{*}{$\begin{array}{l}\text { Case Number } \\
\text { (figure number) }\end{array}$} & \multicolumn{8}{|c|}{ Pressures (mm Hg) } & \multirow[t]{2}{*}{$\begin{array}{l}\text { AV Area } \\
\left(\mathrm{cm}^{2}\right)\end{array}$} & \multirow[t]{2}{*}{$\begin{array}{l}\text { MV Area } \\
\left(\mathrm{cm}^{2}\right)\end{array}$} & \multirow[t]{2}{*}{$\begin{array}{c}\text { MR } \\
(0-4+)\end{array}$} & \multirow[t]{2}{*}{$\begin{array}{c}\text { AR } \\
(0-4+)\end{array}$} & \multirow[t]{2}{*}{$\mathrm{EF}(\%)$} & \multirow[t]{2}{*}{$\begin{array}{c}\text { AV } \\
\text { Weight (g) }\end{array}$} & \multirow[t]{2}{*}{$\begin{array}{c}\text { MV } \\
\text { Weight (g) }\end{array}$} & \multicolumn{2}{|c|}{$\begin{array}{l}\text { Type (size }[\mathrm{mm}] \text { ) } \\
\text { Substitute Valve }\end{array}$} \\
\hline & $\begin{array}{l}\mathrm{LV} \\
(\mathrm{s} / \mathrm{d})\end{array}$ & $\begin{array}{l}\text { Ao } \\
(\mathrm{s} / \mathrm{d})\end{array}$ & $\begin{array}{l}\text { LV-Ao } \\
\text { (psg) }\end{array}$ & $\begin{array}{c}\text { LV-Ao } \\
(\mathrm{msg})\end{array}$ & $\begin{array}{l}\text { LV-MV } \\
\text { (mdg) }\end{array}$ & $\begin{array}{l}\mathrm{RV} \\
(\mathrm{s} / \mathrm{d})\end{array}$ & $\begin{array}{c}\mathrm{RA} \\
\text { (Mean) }\end{array}$ & $\begin{array}{c}\text { PW } \\
\text { (Mean) }\end{array}$ & & & & & & & & $\mathrm{AV}$ & MV \\
\hline $1(2)$ & - & - & - & - & - & - & - & - & 0.9 & 1.8 & - & - & - & - & - & $\mathrm{P}(20)$ & $\mathrm{P}(27)$ \\
\hline 2 & $173 / 40$ & $146 / 88$ & 27 & 30 & 25 & $56 / 18$ & 13 & 39 & 1.0 & 1.28 & $2+$ & $1+$ & 50 & - & - & $\mathrm{P}(21)$ & P (27) \\
\hline $3(3)$ & $139 / 17$ & $133 / 88$ & 6 & 54 & 15 & $48 / 18$ & 13 & 26 & 0.46 & 0.95 & - & $2+$ & 55 & 1.37 & 3.44 & $\mathrm{P}(23)$ & $\mathrm{P}(31)$ \\
\hline $4(4)$ & $226 / 19$ & $195 / 85$ & 31 & 129 & 14 & $79 / 17$ & 54 & 33 & 0.53 & 0.95 & 0 & $2+$ & 60 & - & - & $\mathrm{P}(21)$ & P (29) \\
\hline $5(5)$ & $159 / 27$ & $140 / 65$ & 19 & - & 6 & $57 / 21$ & 20 & 22 & 1.1 & 2.33 & - & - & 20 & 2.54 & 3.70 & B (27) & B (29) \\
\hline $6(6)$ & $163 / 17$ & $124 / 56$ & 39 & 46 & 14 & $99 / 28$ & 18 & 36 & 0.39 & - & - & $1+$ & 70 & 0.90 & 1.00 & $\mathrm{P}(19)$ & $P(25)$ \\
\hline 7 (7) & $180 / 8$ & $148 / 63$ & 32 & 40 & - & - & - & - & 0.77 & - & $4+$ & $2+$ & 70 & 2.40 & 0.90 & $P(25)$ & $P(29)$ \\
\hline $8(8)$ & $234 /$ & $110 /$ & 124 & - & - & $44 / 17$ & 12 & 18 & 0.5 & 1.0 & - & - & 60 & 2.39 & 0.40 & $\mathrm{P}(23)$ & $P(27)$ \\
\hline $9(9)$ & $149 / 38$ & $118 / 64$ & 31 & 21 & - & $34 / 13$ & 5 & 16 & - & - & $4+$ & - & 60 & 2.81 & 4.66 & $\mathrm{P}(25)$ & $\mathrm{P}(33)$ \\
\hline $10(10)$ & $154 / 24$ & $94 / 63$ & 60 & 41 & - & $73 / 24$ & 9 & 29 & 0.52 & - & $4+$ & - & 20 & 5.86 & 0.52 & B (27) & B (29) \\
\hline $11(11)$ & - & $125 / 79$ & - & - & - & $49 / 12$ & 7 & 21 & - & - & $1+$ & $4+$ & - & 5.20 & 5.09 & $\mathrm{P}(24)$ & P (33) \\
\hline 12 & $142 / 8$ & $134 / 78$ & 8 & - & - & $58 / 14$ & - & - & - & - & $4+$ & $2+$ & 40 & - & - & $\mathrm{P}(-)$ & $\mathrm{P}(-)$ \\
\hline $13(12)$ & - & $130 / 60^{*}$ & - & - & - & - & - & - & - & - & $4+$ & $4+$ & - & 1.55 & 0.67 & $P(25)$ & P (29) \\
\hline $14(13)$ & - & $116 / 61$ & - & - & - & $28 / 11$ & 6 & 8 & - & - & - & $3+$ & 60 & 1.30 & 1.28 & $\mathrm{P}(25)$ & $\mathrm{P}(31)$ \\
\hline 15 & - & $100 / 60 *$ & - & - & - & - & - & - & - & - & - & - & 60 & - & - & B (25) & B (29) \\
\hline $16(14)$ & - & $120 / 60 *$ & - & - & - & - & - & - & - & - & - & - & - & 1.02 & 2.01 & B (23) & B (31) \\
\hline
\end{tabular}

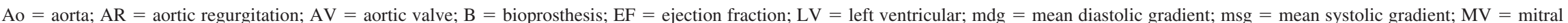
valve; $\mathrm{P}=$ prosthesis; $\mathrm{psg}=$ peak systolic gradient; $\mathrm{PW}=$ pulmonary wedge; $\mathrm{RA}=$ right atrial; $\mathrm{RV}=$ right ventricular; s/d = peak systolic/end-diastolic.

* Indirect pressure. 


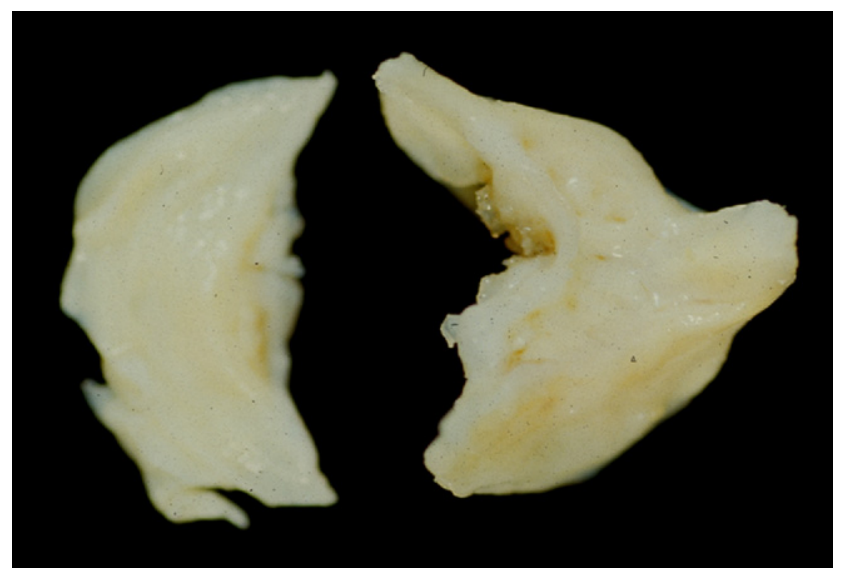

Figure 2. Case 1. Bicuspid aortic valve in a 53-year-old woman with combined mitral and aortic valve stenosis. The mitral valve was diffusely thickened by fibrous tissue and was devoid of calcified deposits; it was excised in multiple pieces. The aortic valve, in contrast, contained calcific deposits covered by thick fibrous tissue. and pure MR (no element of stenosis, cases 12 to 16; Tables 1 and 2).

Of the 5 patients with combined AS and MS, the cause of MS appeared to be rheumatic heart disease in 4 and "massive" mitral annular calcium in 1 (case 5). ${ }^{2}$ Of the 6 patients with AS and pure MR, the latter was attributed to mitral valve prolapse in 3 (cases 9, 10, and 11), to ischemic origin in 2 (concomitant coronary artery bypass grafting also was performed, cases 6 and 7), and in case 8 the cause of MR was unclear, possibly "functional." The latter patient (case 8) had severe AS with a peak left ventricular pressure of $234 \mathrm{~mm} \mathrm{Hg}$ and a body mass index of $42 \mathrm{~kg} / \mathrm{m}^{2}$. Whether either finding or the 2 findings played a role in MR is unclear.

In the 5 patients with combined AR and MR, the cause of MR in 1 patient was mitral valve prolapse (case 12), and in the other 4, infective endocarditis (cases 13 to 16). In each of these latter 4 patients examination of noninfected portions of the cusps suggested that function of the aortic and mitral valves before the onset of active infective endocarditis was probably normal.

Weights of most operatively excised mitral and aortic valves are listed in Table 2. All patients had excision of the

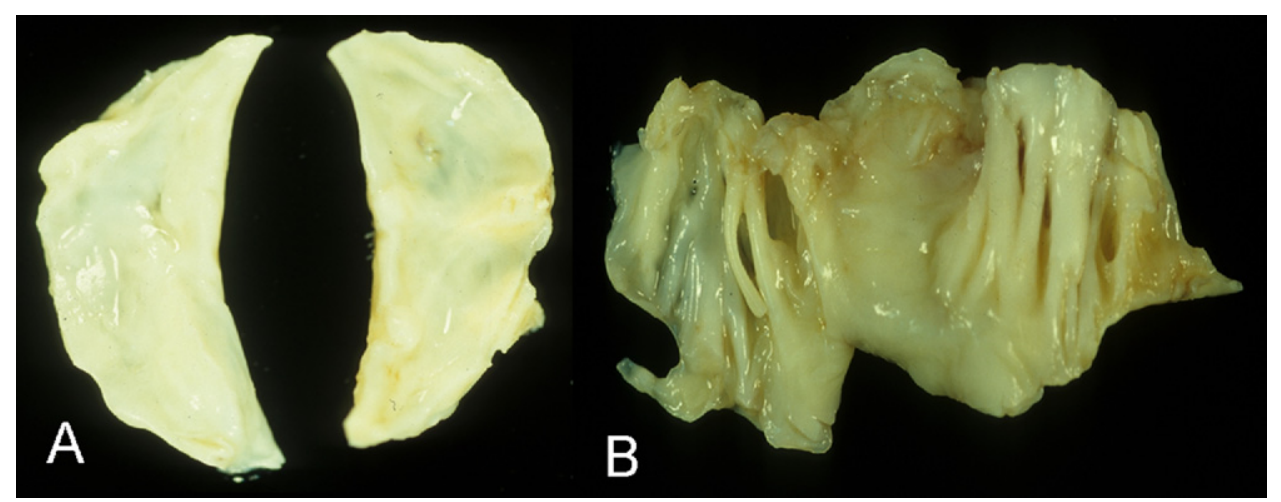

Figure 3. Case 3. Bicuspid stenotic aortic valve $(A)$ and thickened mitral valve $(B)$ in a 46-year-old man. The mitral valve is consistent with rheumatic stenosis. The aortic valve weighed $1.37 \mathrm{~g}$ (normal $<0.50 \mathrm{~g}$ ) and the excised anterior mitral leaflet weighted $3.44 \mathrm{~g}$.

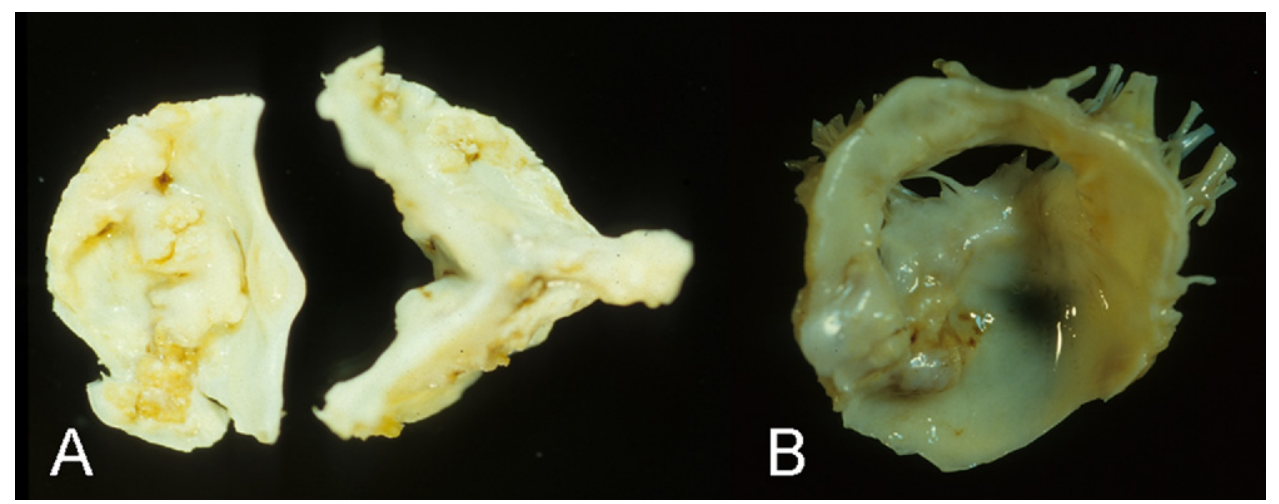

Figure 4. Case 4. Bicuspid stenotic valve $(A)$ and stenotic mitral valve $(B)$. The 2 valves were excised entirely intact. 


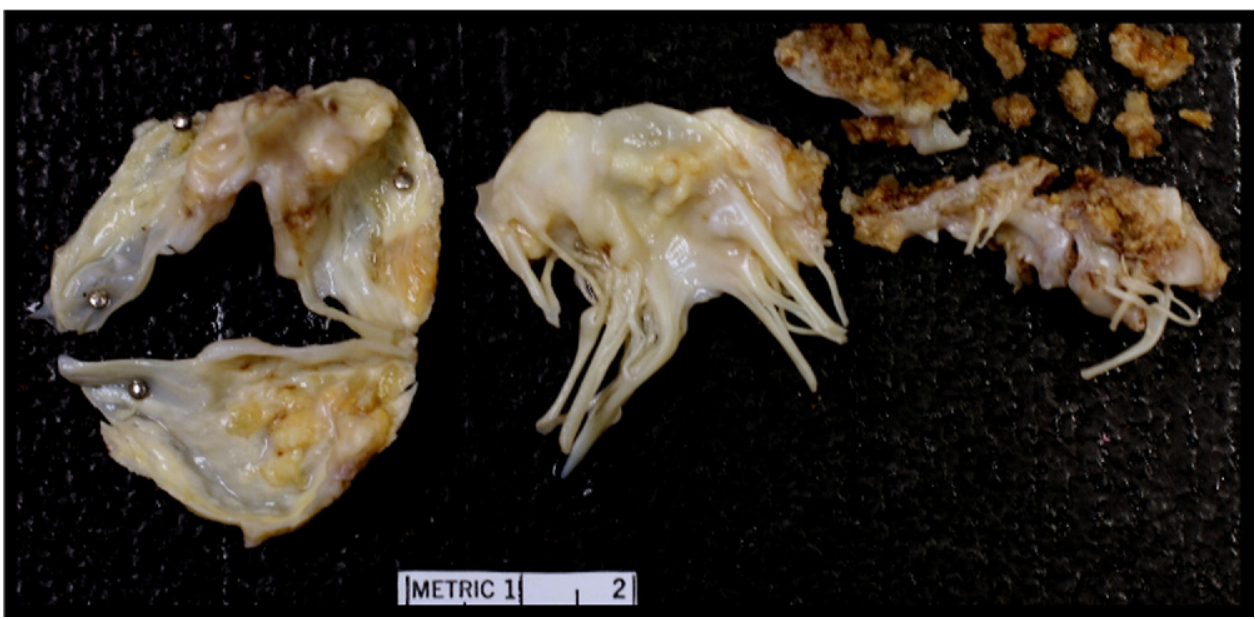

Figure 5. Case 5. Congenitally bicuspid aortic valve, ventricular aspect of anterior mitral leaflet, and portions of posterior leaflet with calcific fragments from the mitral annulus in a 71-year-old man with combined aortic stenosis and mitral stenosis. The latter was the result of heavy calcific deposits on the mitral annular region.

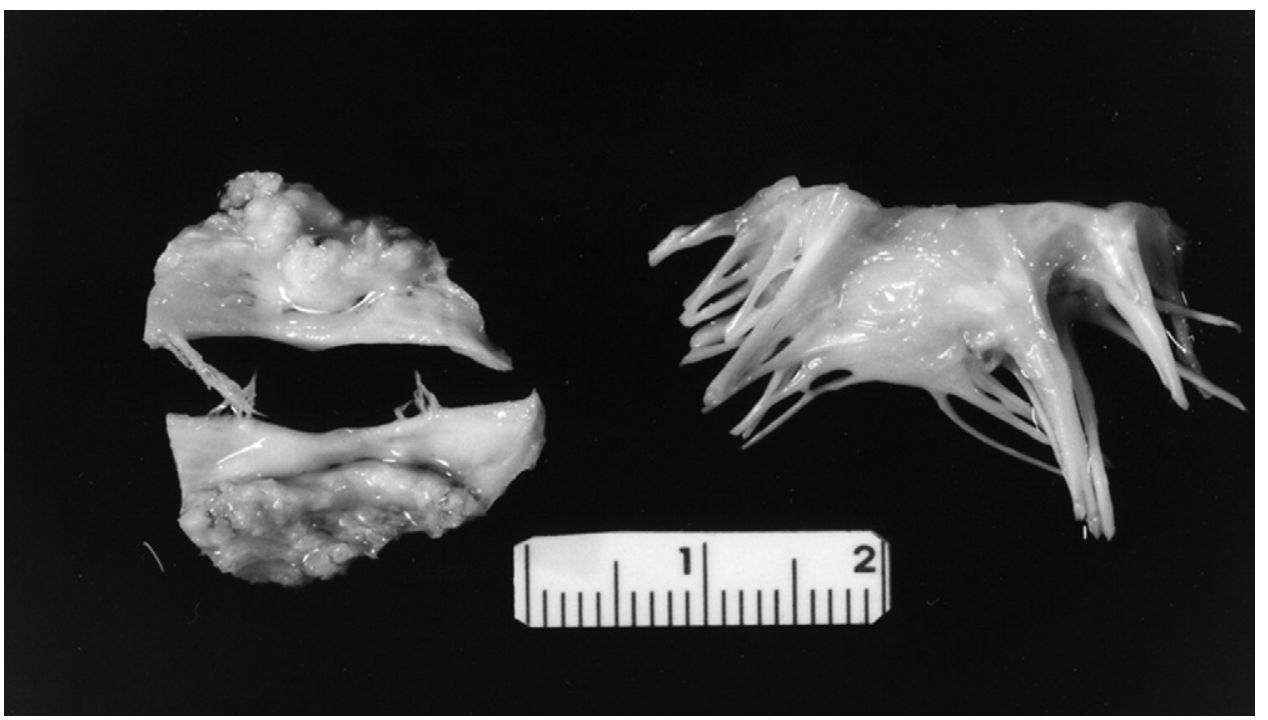

Figure 6. Case 6. Bicuspid aortic valve and anterior mitral leaflet (ventricular aspect) in an 84-year-old woman. The aortic valve is calcified (weight $0.90 \mathrm{~g}$ ) and stenotic. The mitral leaflet is focally thickened as seen typically in ischemic mitral regurgitation.

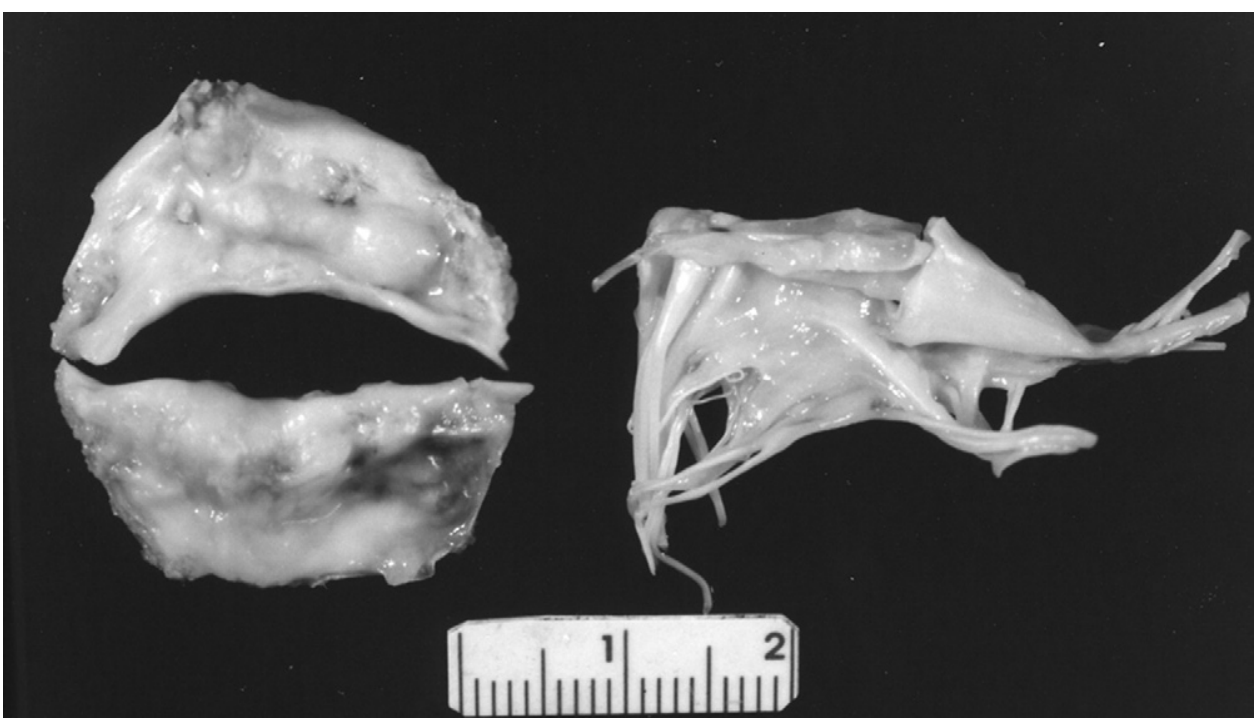

Figure 7. Case 7. Bicuspid aortic valve (left) and ventricular aspect of anterior mitral leaflet (right) in a 77-year-old man with aortic stenosis, mitral regurgitation, and severe coronary artery disease necessitating concomitant coronary artery bypass grafting. The mitral valve shows changes consistent with ischemic mitral regurgitation. 


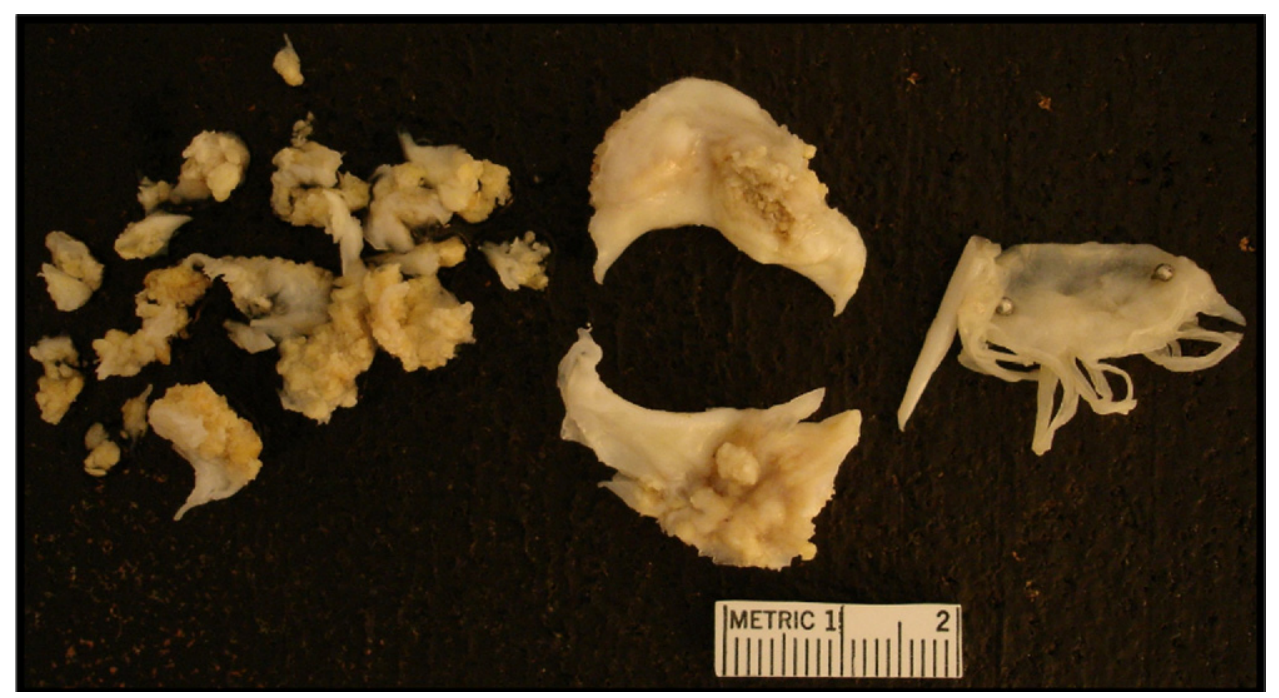

Figure 8. Case 8. Calcific fragments from aortic valve (left), 2 aortic valve cusps (middle), and atrial aspect of anterior mitral leaflet (right) in a 58-year-old woman with aortic stenosis and pure mitral regurgitation, the latter of uncertain origin. The coronary arteries angiographically were normal and there were no calcific deposits in the mitral annular region.

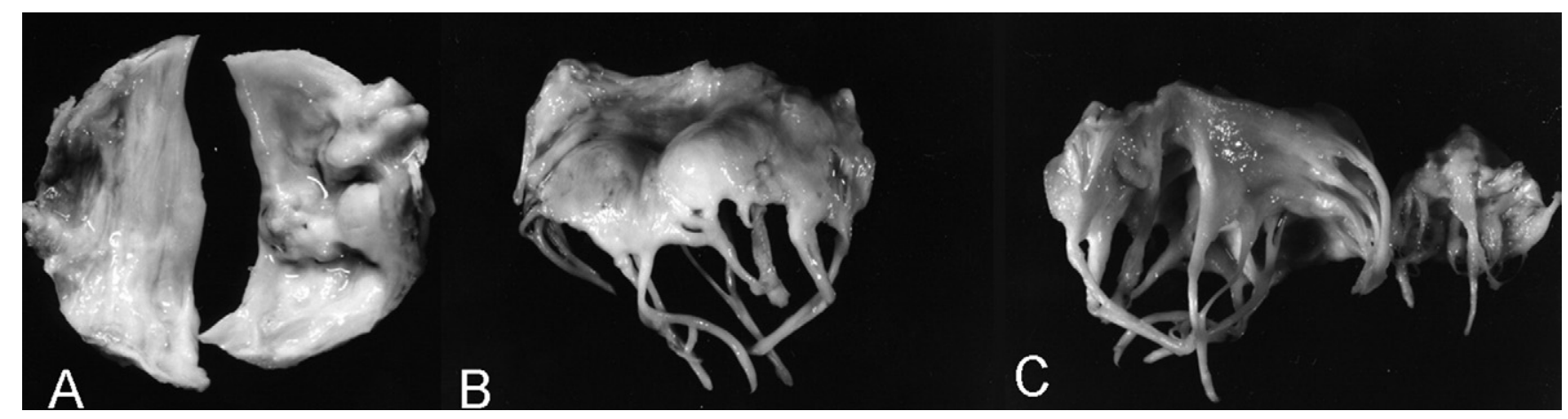

Figure 9. Case 9. Congenitally bicuspid and stenotic aortic valve (A), atrial aspect of anterior mitral leaflet displaying a scallop (B), and ventricular aspect of anterior mitral leaflet and a portion of posterior leaflet $(C)$ in a 68-year-old man. The mitral changes are characteristic of mitral valve prolapse.

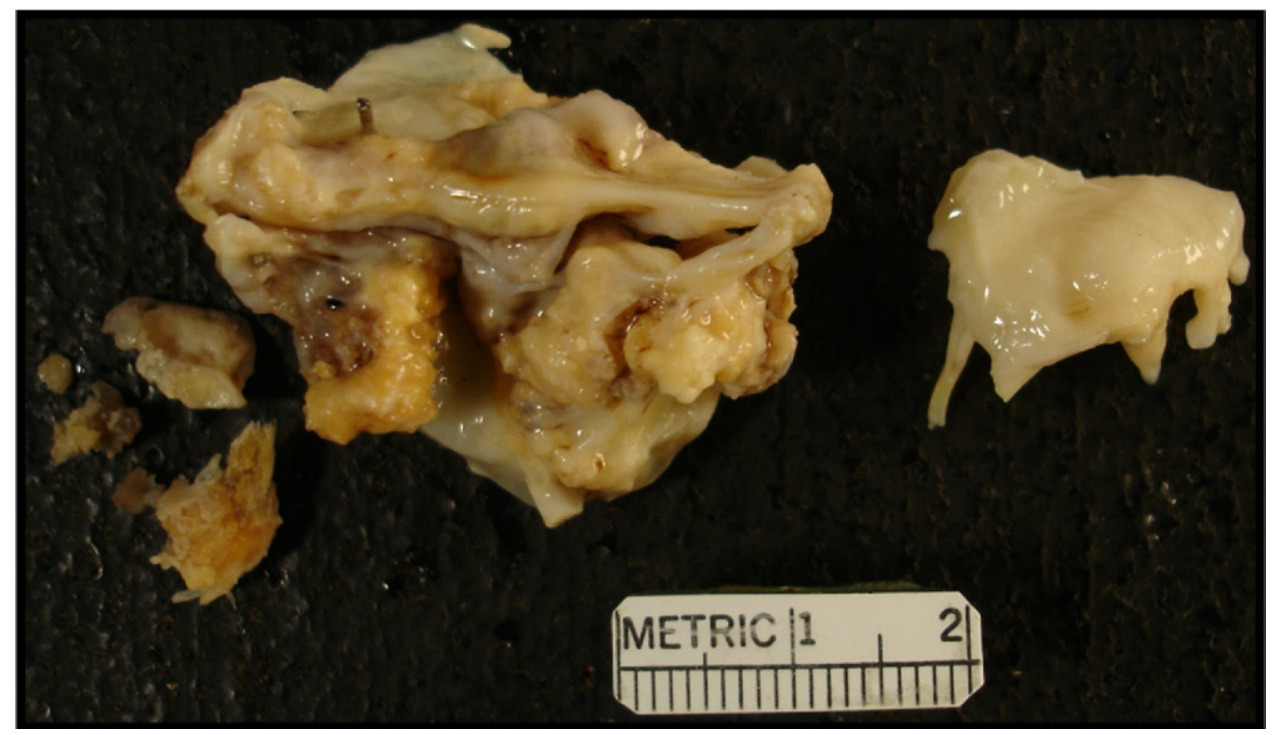

Figure 10. Case 10. Heavily calcified (5.86 g) congenitally bicuspid aortic valve (left) and fragment of posterior mitral leaflet (right) in a 67-year-old man with severe aortic stenosis and pure mitral regurgitation, the consequence of mitral valve prolapse. 


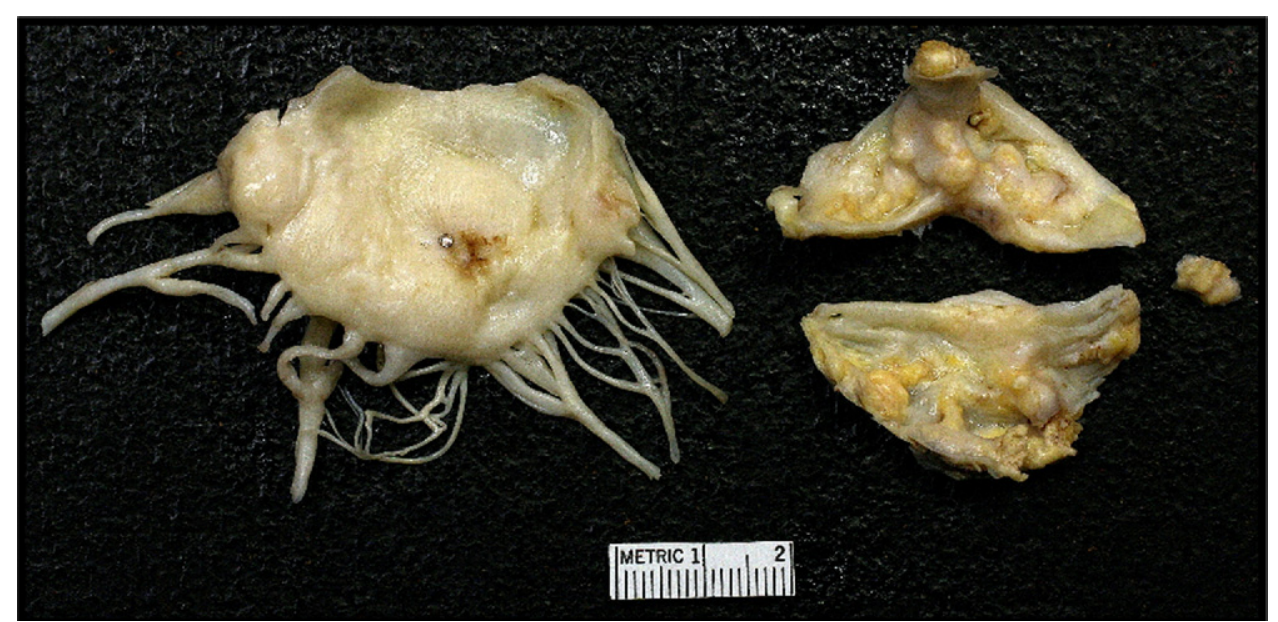

Figure 11. Case 11. Atrial aspect of anterior mitral leaflet (left) and heavily calcified (weight $5.86 \mathrm{~g}$ ) congenitally bicuspid aortic valve (right) in a 66-year-old man. The mitral valve was purely regurgitant because of mitral valve prolapse and the aortic valve was severely stenotic.

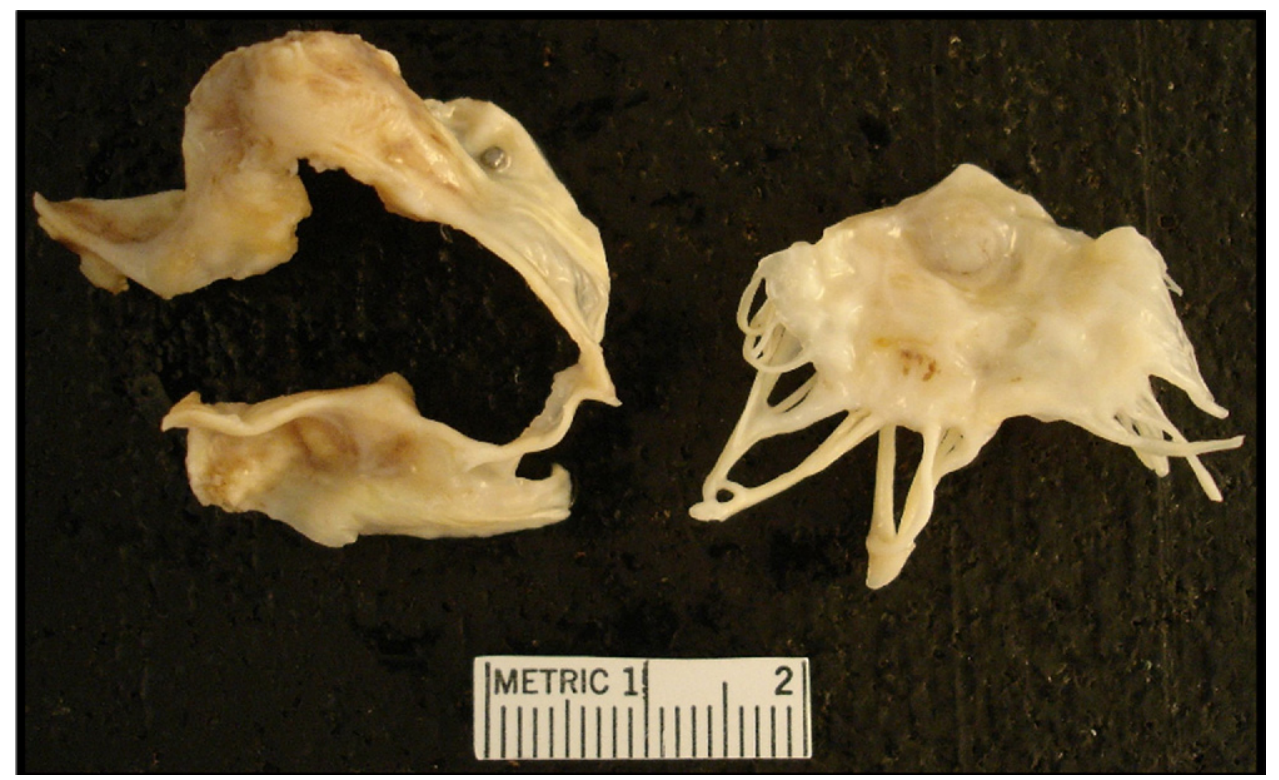

Figure 12. Case 13. Congenitally bicuspid aortic valve (left) and atrial aspect of anterior mitral leaflet (right) in a 66-year-old man with pure aortic regurgitation and pure mitral regurgitation secondary to Streptococcus bovis endocarditis, which is healing. Histologic sections of the valves disclosed fibrin, collections of polymorphonuclear leukocytes, but no microorganisms. He had been receiving antibiotics.

anterior mitral leaflet, and 3 (cases 4, 5, and 9) also had excision of the posterior mitral leaflet.

Type of substitute cardiac valve employed in the 16 patients also is presented in Table 2: in 12 patients a mechanical prosthesis was used in the 2 valve positions and in the other 4 patients (cases 5, 10, 15, and 16) a bioprostheses was used in the 2 valve positions. Various sizes of the prostheses and bioprostheses employed also are presented in Table 2. The interval from valve replacement to hospital discharge in the 16 patients varied from 4 to 56 days (mean 12, median 7). Eight of the 16 patients have died. Intervals from valve replacement to death ranged from 1.3 to 13.3 years (mean 6.3, median 5.6). The other 8 patients are alive (as of June 30,2011) and their intervals from valve replacement have ranged from 1.8 to 16.7 years (mean 7.2, median 4.5).

\section{Discussion}

This study demonstrates that some patients with congenitally bicuspid aortic valves have dysfunctioning mitral valves that lead not only to replacement of the aortic valve but also to replacement of the mitral valve. Of 162 patients having replacement of the 2 left-sided valves at BUMC in Dallas during the previous 17 years, $16(10 \%)$ had congenitally bicuspid aortic valves and malfunctioning mitral valves. In 11 of the 16 patients, the aortic valve was stenotic: in 5 of them, the mitral valve was also stenotic, the apparent result of rheumatic heart disease in 4 and mitral annular calcium in 1; in the other 6 patients with AS, MR was the result of mitral valve prolapse in 3 , of ischemic disease in 2, and from uncertain cause in 1 . All 5 patients with pure AR also had pure MR, the consequence of mitral 


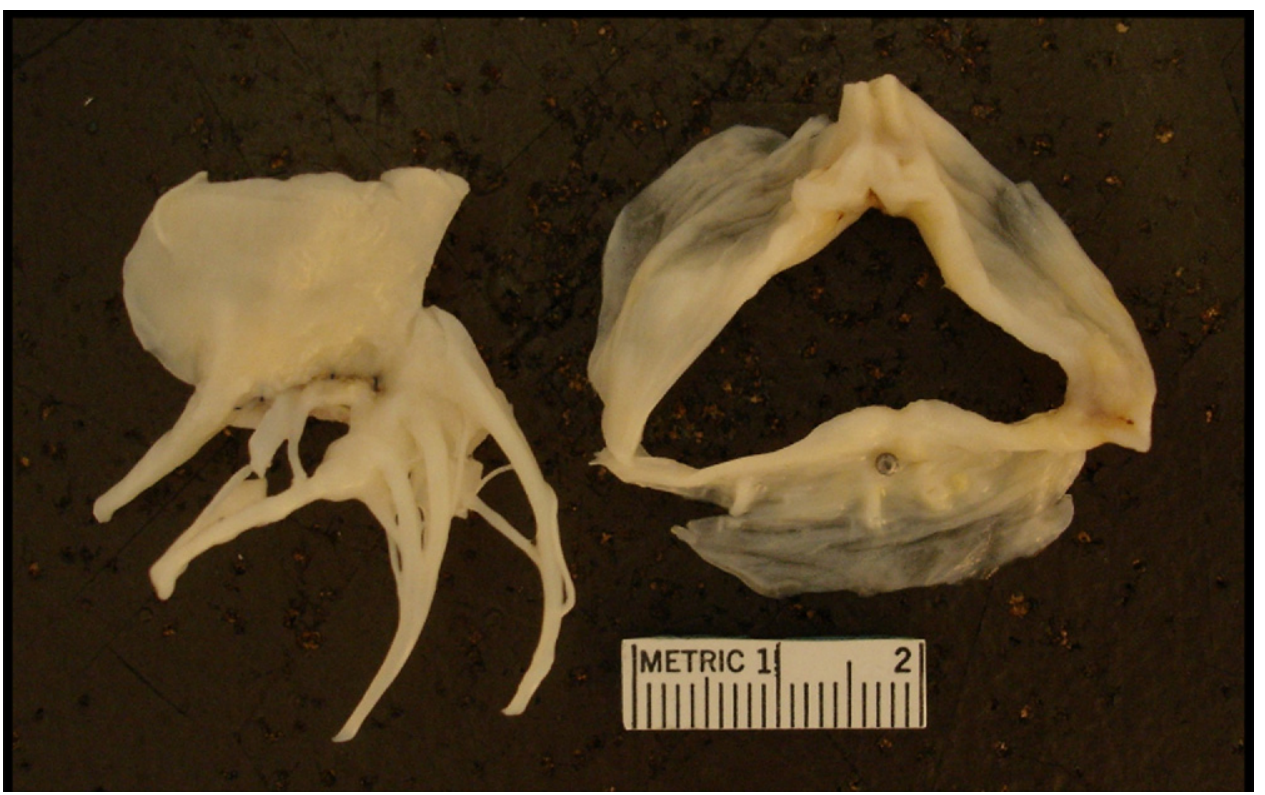

Figure 13. Case 14. Fragment of anterior mitral leaflet (left) and congenitally bicuspid aortic valve (right) in a 47-year-old man who had had 2 episodes of Streptococcus viridans before double-valve replacement for pure mitral regurgitation and pure aortic regurgitation.

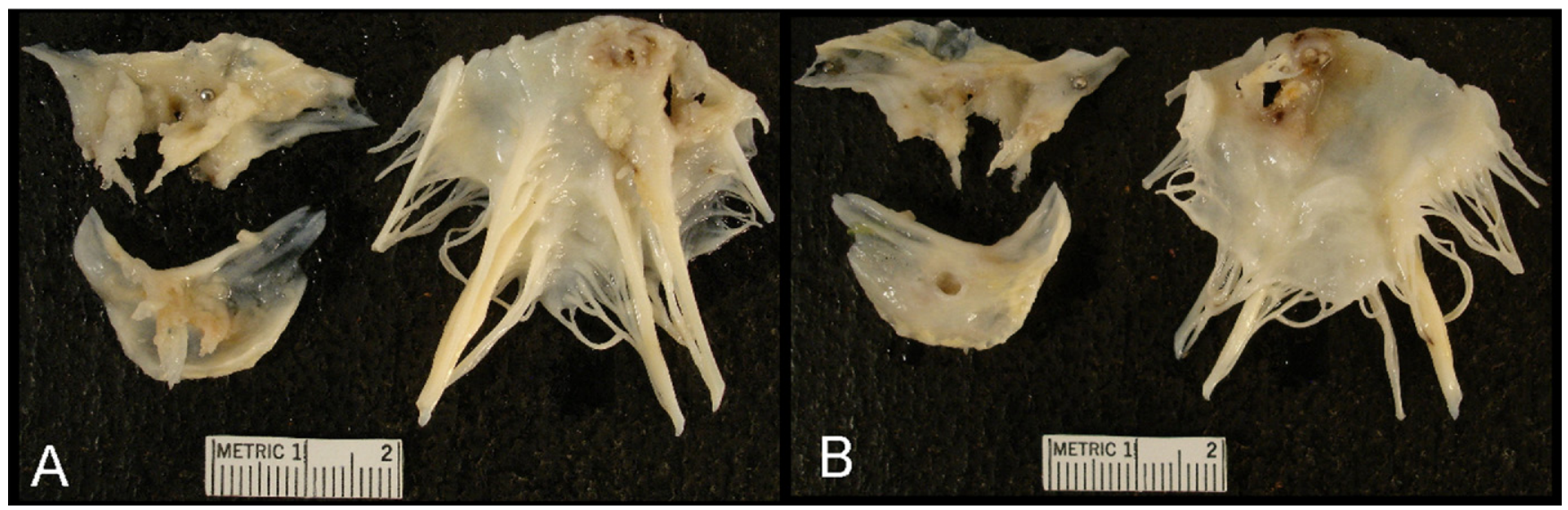

Figure 14. Case 16. Infected congenitally bicuspid aortic valve and anterior mitral leaflet in a 50-year-old with pure aortic and mitral regurgitation secondary to Streptococcus viridans endocarditis. (A) Aortic aspect of the aortic valve and ventricular aspect of the anterior mitral leaflet. (B) Ventricular aspect of the aortic valve cusps and atrial aspect of the anterior mitral leaflet again showing the perforations.

valve prolapse in 1 and infective endocarditis in 4 . It is well recognized that infection on the aortic valve often extends to involve the mitral valve, causing regurgitation in each. ${ }^{3}$

The occurrence of 2 different types of congenital heart disease in the same heart is a common occurrence but not so for bicuspid aortic valve and mitral valve prolapse as occurred in 4 of our 16 patients. If mitral valve prolapse occurs in about $5 \%$ of the United States population (roughly 15 million people) and if bicuspid aortic valve occurs in $1 \%$ of this population (roughly 3 million people), it should not be surprising that the 2 conditions might occur periodically in the same patient. One of our patients (case 3) also had aortic isthmic coarctation, a well-recognized coexisting congenital lesion in patients with congenitally bicuspid aortic valves. ${ }^{4}$

The present report is not the first to describe mitral valve prolapse in patients with bicuspid aortic valves. Fernicola and Roberts ${ }^{1}$ in 1994 described 11 men age 25 to 77 who had aortic and mitral valve replacements for dysfunctioning congenitally bicuspid aortic valves (AS in 7, pure AR in 4) associated with pure MR (secondary to mitral valve prolapse in 6 and to infective endocarditis in 5). Schaefer et $\mathrm{al}^{5}$ in 2002 found by echocardiogram "myxomatous mitral valve" in 9 of 192 adults (5\%) with bicuspid aortic valves, most of which apparently functioned normally or were purely regurgitant. Lad et $\mathrm{al}^{6}$ described first-time operations for MR secondary to "myxomatous degeneration" in 1,595 patients and operations for congenitally bicuspid aortic valves in 1,820 patients; of the 3,415 patients, 29 (1\%) had a congenitally bicuspid aortic valve and "degenerative disease" of the mitral valve. Of the 29 patients, $8(28 \%)$ had AS and $21(72 \%)$ had AR. Of these 29 patients, the mitral valve was repaired in 24 and replaced in 5; the bicuspid aortic valve was repaired in 10 patients and replaced in 19 . The mitral annulus was dilated in all but 1 of their 29 patients and the anterior mitral leaflet was elongated in 22 of these 29 patients. 
1. Fernicola DJ, Roberts WC. Pure mitral regurgitation associated with a malfunctioning congenitally bicuspid aortic valve necessitating combined mitral and aortic valve replacement. Am J Cardiol 1994;74:619624.

2. Hammer WJ, Roberts WC, deLeon AC Jr. "Mitral stenosis" secondary to combined "massive" mitral anular calcific deposits and small, hypertrophied left ventricles. Hemodynamic documentation in four patients. Am J Med 1978;64:371-376.

3. Buchbinder NA, Roberts WC. Left-sided valvular active infective endocarditis. A study of forty-five necropsy patients. Am J Med 1972;53:20-35.
4. Glancy DL, Morrow AG, Simon AL, Roberts WC. Juxtaductal aortic coarctation. Analysis of 84 patients studied hemodynamically, angiographically, and morphologically after age 1 year. Am J Cardiol 1983 51:537-551.

5. Schaefer BM, Lewin MB, Stout KK, Gill E, Prueitt A, Byers PH, Otto $\mathrm{CM}$. The bicuspid aortic valve: an integrated phenotypic classification of leaflet morphology and aortic root shape. Heart 2008;94:1634-1638.

6. Lad V, David TE, Vegas A. Mitral regurgitation due to myxomatous degeneration combined with bicuspid aortic valve disease is often due to prolapse of the anterior leaflet of the mitral valve. Ann Thorac Surg 2009;87:79-82. 